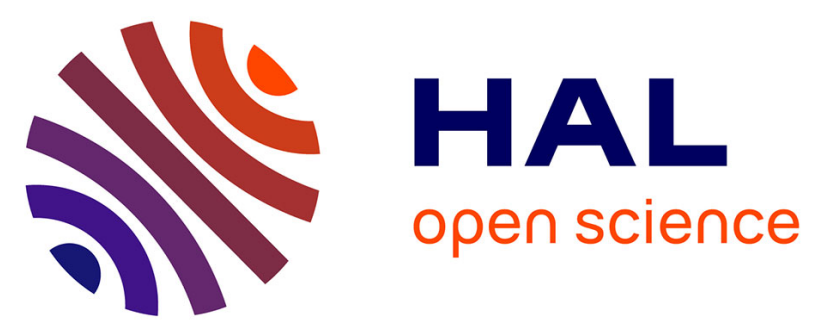

\title{
Self-assembled Titanium Calcium Oxide Nanopatterns as versatile Reactive Nanomasks for Dry Etching Lithographic Transfer with High Selectivity
}

\author{
Marco Faustini, Glenna L. Drisko, Alban A. Letailleur, Rafael Salas-Montiel,
} Cédric Boissière, Andréa Catoni, Anne Marie Haghiri-Gosnet, Gilles Lerondel, David Grosso

\section{To cite this version:}

Marco Faustini, Glenna L. Drisko, Alban A. Letailleur, Rafael Salas-Montiel, Cédric Boissière, et al.. Self-assembled Titanium Calcium Oxide Nanopatterns as versatile Reactive Nanomasks for Dry Etching Lithographic Transfer with High Selectivity. Nanoscale Research Letters, 2013, 5 (3), pp.984990. 10.1039/C2NR33341D . hal-00759965

\section{HAL Id: hal-00759965 https://hal.science/hal-00759965}

Submitted on 3 Dec 2012

HAL is a multi-disciplinary open access archive for the deposit and dissemination of scientific research documents, whether they are published or not. The documents may come from teaching and research institutions in France or abroad, or from public or private research centers.
L'archive ouverte pluridisciplinaire HAL, est destinée au dépôt et à la diffusion de documents scientifiques de niveau recherche, publiés ou non, émanant des établissements d'enseignement et de recherche français ou étrangers, des laboratoires publics ou privés. 


\section{Accepted Manuscript}

\section{Nanoscale}

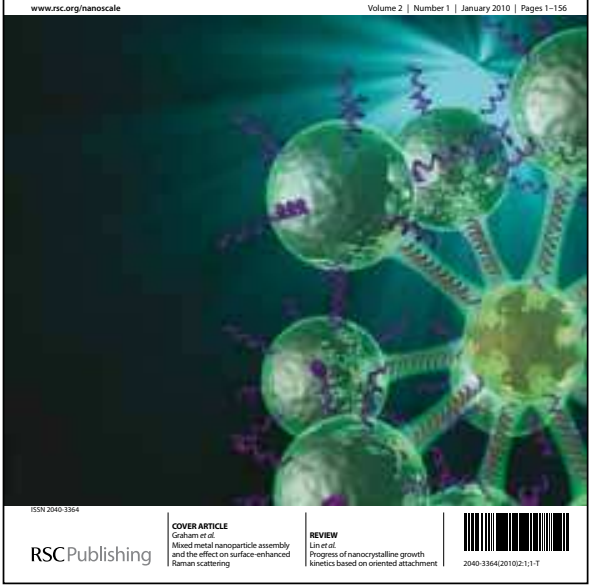

This is an Accepted Manuscript, which has been through the RSC Publishing peer review process and has been accepted for publication.

Accepted Manuscripts are published online shortly after acceptance, which is prior to technical editing, formatting and proof reading. This free service from RSC Publishing allows authors to make their results available to the community, in citable form, before publication of the edited article. This Accepted Manuscript will be replaced by the edited and formatted Advance Article as soon as this is available.

To cite this manuscript please use its permanent Digital Object Identifier $\left(\left.\mathrm{DO}\right|^{\oplus}\right)$, which is identical for all formats of publication.

More information about Accepted Manuscripts can be found in the

\section{Information for Authors.}

Please note that technical editing may introduce minor changes to the text and/or graphics contained in the manuscript submitted by the author(s) which may alter content, and that the standard Terms \& Conditions and the ethical guidelines that apply to the journal are still applicable. In no event shall the RSC be held responsible for any errors or omissions in these Accepted Manuscript manuscripts or any consequences arising from the use of any information contained in them. 


\title{
Self-assembled Titanium Calcium Oxide Nanopatterns as
}

\section{versatile Reactive Nanomasks for Dry Etching Lithographic}

\section{Transfer with High Selectivity}

\begin{abstract}
Marco Faustini, ${ }^{a}$ Glenna L. Drisko, ${ }^{a}$ Alban A. Letailleur, ${ }^{\text {a,b }}$ Rafael Salas Montiel, ${ }^{\text {c }}$ Cédric Boissière, ${ }^{a}$ Andrea Cattoni, ${ }^{d}$ Anne Marie Haghiri-Gosnet, ${ }^{d}$ Gilles Lerondel, ${ }^{\text {c }}$ and David Grosso ${ }^{\text {a }}$,
\end{abstract}

${ }^{\text {a }}$ Laboratoire Chimie de la Matière Condensée, UMR UPMC-Collège de France-CNRS 7574. Collège de France, 11 place Marcelin Berthelot, 75231 Paris. david.grosso@upmc.fr

${ }^{\mathrm{b}}$ Surface du Verre et Interfaces, UMR CNRS/Saint-Gobain 125, 39 quai Lucien Lefranc, 93303 Aubervilliers, France

${ }^{\mathrm{c}}$ Laboratoire de Nanotechnologie et d'Instrumentation Optique, Institut Charles Delaunay, CNRS UMR STMR 6279, Université de Technologie de Troyes, 12 rue Marie Curie, BP2060, Troyes cedex

${ }^{\mathrm{d}}$ Laboratoire de Photonique et de Nanostructures, LPN, route de Nozay, 91460 Marcoussis, France. 
We report the simple preparation of ultra-thin self-assembled nanoperforated titanium calcium oxide films and their use as Reactive NanoMasks for selective dry etching of silicon. The novel reactive nanomask is composed of $\mathrm{TiO}_{2}$ to which up to $50 \%$ of $\mathrm{Ti}$ was replaced by $\mathrm{Ca}\left(\mathrm{Ca}_{\mathrm{x}} \operatorname{Ti}_{(1-\mathrm{x})} \mathrm{O}_{(2-\mathrm{x})}\right)$. The system has been prepared by evaporation induced self-assembly of dip-coated solution of $\mathrm{CaCl}_{2}, \mathrm{TiCl}_{4}$ and poly(butadiene-block-ethylene oxide) followed by $5 \mathrm{~min}$ of thermal treatment at $500{ }^{\circ} \mathrm{C}$ in air. The mask exhibits enhanced selectivity by forming a $\mathrm{CaF}_{2}$ protective layer in the presence of a chemically reactive fluorinated plasma. In particular it is demonstrated that ordered nano-arrays of dense Si pillars, or deep cylindrical wells, with high aspect ratio i.e. lateral dimensions as small as $20 \mathrm{~nm}$ and height up to $200 \mathrm{~nm}$, can be formed. Both wells and pillars were formed by tuning the morphology and the homogeneity of the deposited mask. The mask preparation is extremely fast and simple, low-cost and easily scalable. Its combination with reactive ion etching constitutes one of the first examples of what can be achieved when sol-gel chemistry is coupled with top-down technologies. The resulting $\mathrm{Si}$ nanopatterns and nanostructures are of high interest for applications in many fields of nanotechnology including electronics and optics. This work extends and diversifies the toolbox of nanofabrication methods. 
The development of bottom-up methods to prepare large nanopatterned surfaces at low-cost has become one of the priorities in nanotechnology. ${ }^{1}$ The market of organic and large area electronics, covering important topics like lighting, organic photovoltaics, displays, electronics and integrated smart systems has potential up to a few hundred billion USD in the subsequent decades according to IDTechEx, a leading research company. ${ }^{2}$ Despite the potential economic and social benefits, several technological barriers exist to producing and commercializing such devices. Top-down lithographic approaches yield extremely well resolved features, arrays of periodical patterns with dimension from several microns as small as $20 \mathrm{~nm}$ and long-range order. ${ }^{3-6}$ However the lithographic processes that achieve sub-100 nm resolutions, such Electron Beam Lithography, are slow, costly and low throughput and thus not directly appropriate for industrial production on large surfaces. Low-cost synthetic bottomup approaches are capable of self-assembling organic ${ }^{7}$ and inorganic ${ }^{8}$ materials of much smaller dimensions, but they suffer from poor long range order and the presence of localised points and extended defects. However, these self-assembled materials can easily be deposited onto various surfaces including curved surfaces using liquid deposition techniques. They can then be used as a cheap alternative or an intermediate step in conventional nanofabrication protocols. One of the first examples of this combined approach is the nanosphere lithography; the process involves the deposition of selfassembled monolayers of polymeric spheres used as masks that lead to ordered arrays of nanostructures having periodicity in the order of hundreds of nanometers. ${ }^{9,10}$ Nanolithography involving dry reactive ion etching (RIE) through self-assembled block copolymer nanostencils has recently proven to be an efficient approach for transferring 20-50 $\mathrm{nm}$ features with hexagonal or square organisation on $\mathrm{Si}$ wafers. ${ }^{11-14}$ But, polymer nanomasks are delicate to prepare, lack durability and most importantly selectivity. Alternatively Anodised alumina (AA) membranes have also been used to transfer $70 \mathrm{~nm}$ perforations within silicon on insulator substrates to obtain enhanced light emission optical surfaces ${ }^{15-16}$ but their preparation is hard to implement at the industrial scale. In this work, we will show that it is 
possible to overcome the limitations of the above mentioned materials by replacing the blockewapolymer and AA membranes by a sol-gel derived inorganic nanopattern. This generation of novel self-assembled reactive nanomasks (RNM) are robust, simple to prepare and have adjustable chemical composition.

Inorganic nanopatterns (INP) can be prepared by simple dip-coating deposition of a single layer of block copolymer micelles embedded within a sol-gel precursor, followed by a thermal treatment. ${ }^{17} \mathrm{~A}$ careful adjustment of the chemical composition of the initial solution and of the dipping conditions leads to such INP, ${ }^{18-19}$ that are ultrathin (4-15 nm thick) metal oxide layers $\left(\mathrm{TiO}_{2}, \mathrm{Al}_{2} \mathrm{O}_{3}, \mathrm{ZrO}_{2}\right)$ bearing ordered nanoperforations $(12-80 \mathrm{~nm}$ in diameter) through which the surface of the substrate (e.g. Si, glass, FTO, ITO, Au, or any other porous or dense layer) is accessible. They have already been used for selective local growth of nanoobjects, ${ }^{20}$ as surface modifiers for wetting, ${ }^{21}$ as components of selfcleaning anti-reflective layers, ${ }^{22}$ and as nanolectrode arrays. ${ }^{23-24}$

Here we report on how these INP layers can be used as novel RNMs for lithographic transfers though dry etching. The distinctive feature of the latter RNMs is that they can react with the etching plasma to yield a highly stable, and thus highly selective, stencil. More precisely, $\mathrm{TiO}_{2} \mathrm{INP}$ have first been combined with $\mathrm{Ca}^{2+}$ to yield $\mathrm{Ca}_{\mathrm{x}} \mathrm{Ti}_{(1-\mathrm{x})} \mathrm{O}_{(2-\mathrm{x})}$ INP RNMs on $\mathrm{Si}$ wafers. Then, the systems have been processed through by RIE using conventional fluoride-containing gases. We demonstrate that the presence of $\mathrm{Ca}^{2+}$ considerably enhances the chemical selectivity during etching. This is due to the spontaneous reaction of $\mathrm{Ca}^{2+}$ with ionised $\mathrm{F}^{-}$to form $\mathrm{CaF}_{2}$, a solid compound that is extremely stable under the present etching conditions. Depending on the perforations size and the $\mathrm{Ca}^{2+}$ concentration of the initial mask, this simple approach, illustrated in Figure 1, led to ordered arrays of Si vertical pillars or wells, having diameters down to $20 \mathrm{~nm}$ and height, or depth, of $200 \mathrm{~nm}$. The morphology of the surfaces and the efficiency of the process were investigated by electronic microscopy and GI-SAXS while GI-WAXS characterization was used to access the crystalline structure of the ultra-thin layers. 


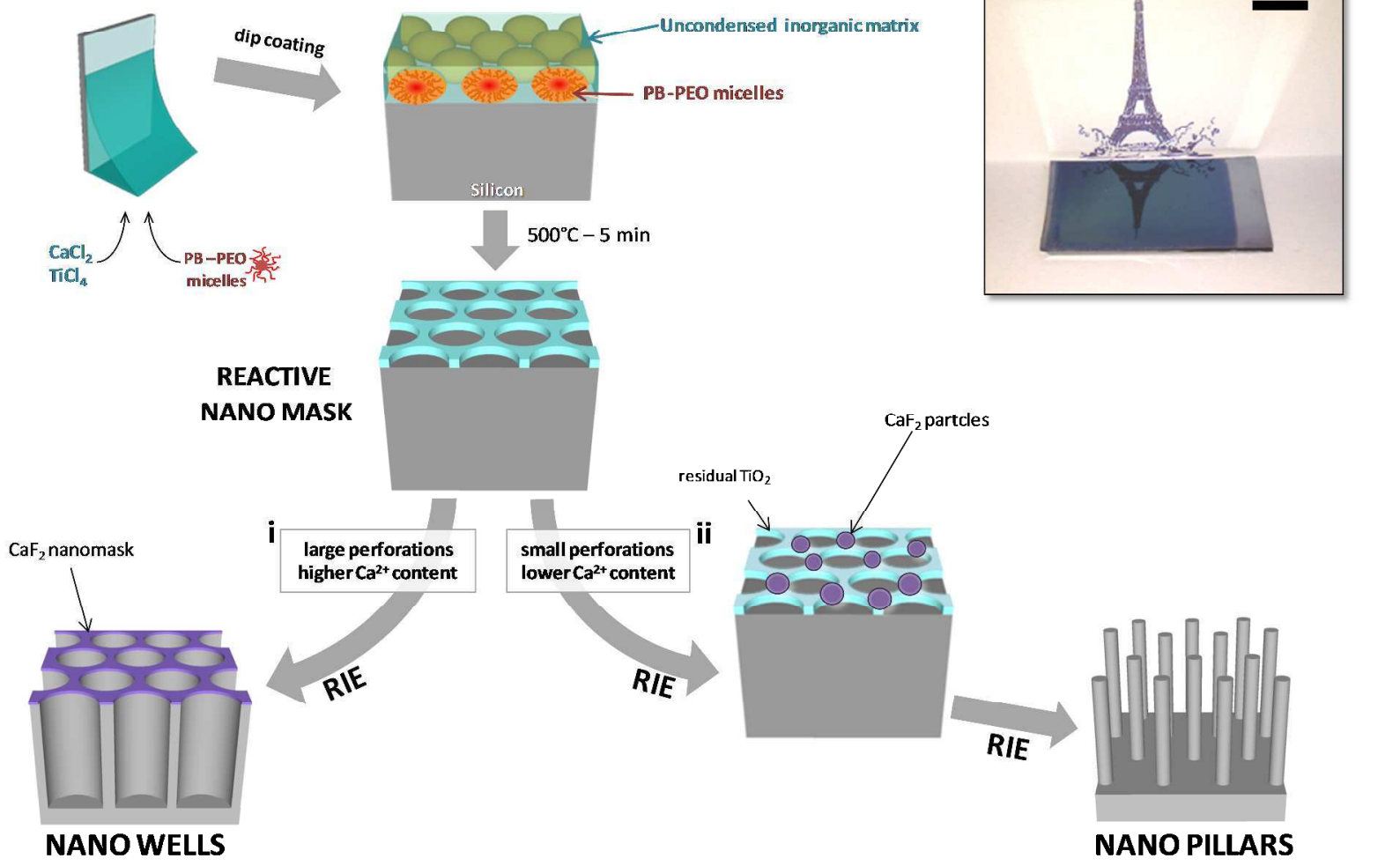

Figure 1. Scheme illustrating the formation of nanowells or nanopillar arrays using the RNM approach. Inset. Photo of a surface after RIE composed by nanowells.
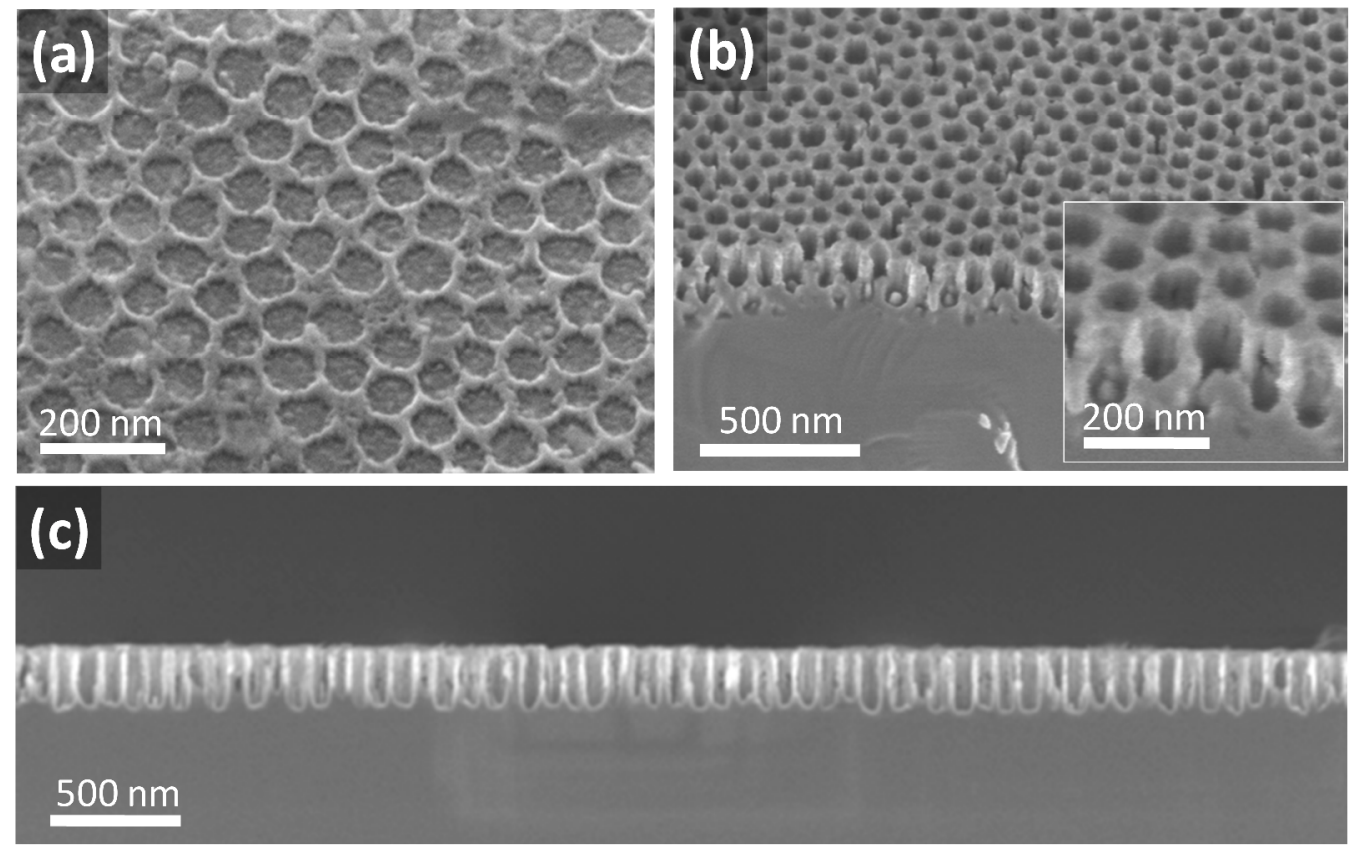

Figure 2. FEG-SEM images of (a) the top view of the initial calcium titanium oxide RNM mask, (b) the surface, and (c) the profile view of the corresponding transferred patterns on Si after etching. 


\section{Results and discussion}

\subsection{First example of patterning: Silicon Nanowells}

Silicon Nanowells were obtained by faithful pattern transfer of the initial RNM having large perforation and higher $\mathrm{Ca}^{2+}$ concentration as illustrated in Figure 1 (route i). The inset of Figure 1shows an example of the patterned samples after etching that looked homogenous and exhibited good optical properties. Figure 2 a displays a SEM image of the surface of a silicon wafer on which a $\mathrm{Ca}_{0,5} \mathrm{Ti}_{0,5} \mathrm{O}_{1,5}$ RNM has been applied. It shows a quasi-compact organisation of round perforations within a continuous solidified network of calcium titanium oxide. In this particular case the perforations have an average diameter of $60 \mathrm{~nm}$ and a RNM wall height of around $10 \mathrm{~nm}$. The surface of the Si wafer is clearly observed at the bottom of the perforations. The analysis of the structure of the initial RNM by GI-WAXS reveals that the latter is amorphous and does not correspond to the thermodynamically stable $\mathrm{CaTiO}_{3}$ perovskite structure. This is likely due to the thermal treatment that is not sufficient to reach the crystalline state, which requires usually extensive heating at $600{ }^{\circ} \mathrm{C}$ or more to be formed. ${ }^{25-26} \mathrm{~A}$ crystalline structure is not desirable in the context of this application, as the amorphous INP has fine, well-defined features and dense walls, and the etching process has high textural sensitivity. After etching in a mixed atmosphere of $\mathrm{SF}_{6} / \mathrm{O}_{2}$ following the conditions given in Table 1, the latter network is transferred with high fidelity to the silicon wafer (Figure $2 b, c$ ). The resulting pattern is composed of cavities with the same diameter as the initial perforations with an etching depth of $250 \mathrm{~nm}$, which corresponds to a depth/diameter aspect ratio of 4 . In the present conditions, the silicon etching reaction leads to the formation of volatile $\mathrm{SiF}_{4}$ and $\mathrm{SiO}_{\mathrm{x}} \mathrm{F}_{\mathrm{y}}$, which deposits at the surface of the vertical $\mathrm{Si}$ wall, acting as a passivating layer and slowing lateral etching. This phenomenon is responsible for the prevalent etching of the bottom of the cavities and the anisotropic etching. ${ }^{27-28}$ More importantly, a 10 
nm thick RNM allows anisotropic etching of at least $250 \mathrm{~nm}$ of the Si wafer semiconductor an etching selectivity of 25 .

Table 1. Conditions used for dry etching.

\begin{tabular}{llllllll}
\hline Program & Equipment & \multicolumn{2}{l}{ Gas flux (sccm) } & & Power & Pressure & Time \\
& Mode & $\mathrm{O}_{2}$ & $\mathrm{SF}_{6}$ & $\mathrm{CHF}_{3}$ & $(\mathrm{~W})$ & (mTorr) & $(\mathrm{min})$ \\
\hline $\mathrm{OF}$ & Plassys (RF) & 7 & 17 & 0 & 80 & 4 & 0.5 \\
$\mathrm{O}$ & Plassys (RF) & 7 & 0 & 0 & 80 & 4 & 0.5 \\
$\mathrm{CF}$ & Nextral & 0 & 4 & 20 & 30 & 30 & 4 \\
\hline
\end{tabular}
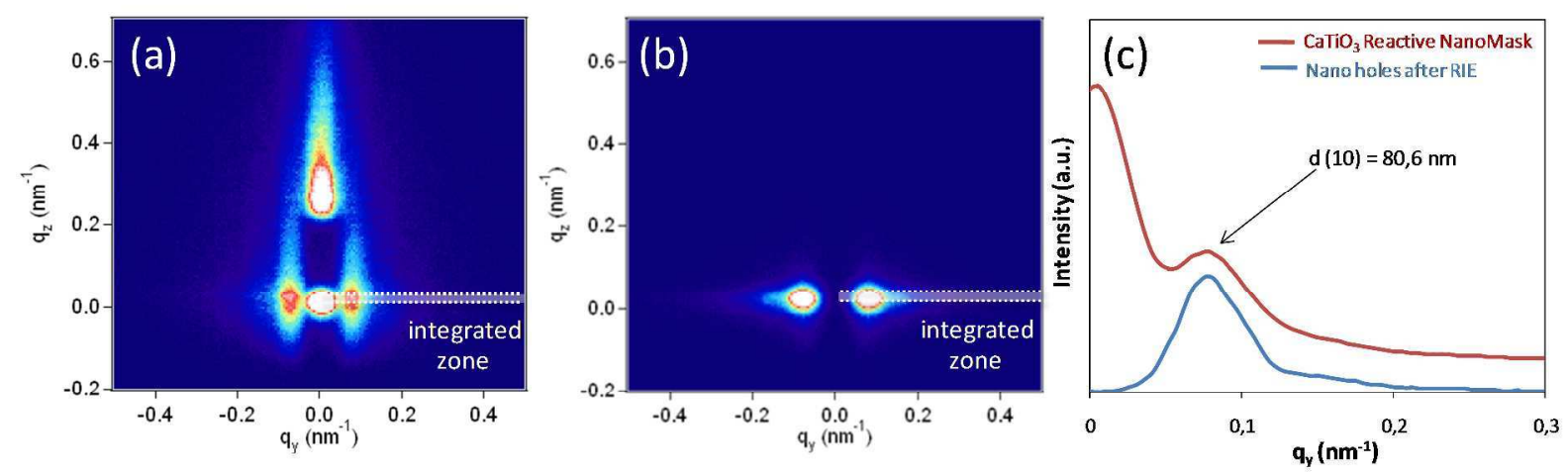

Figure 3. GI-SAXS patterns of (a) the initial $80.6 \mathrm{~nm}$ periodic $\mathrm{Ca}_{0,5} \mathrm{Ti}_{0,5} \mathrm{O}_{1,5} \mathrm{RNM}$ (b) the surface after etching through the latter RNM and (c) the corresponding intensity profiles before (pink line) and after (blue line) etching along the $\mathrm{q}_{\mathrm{y}}$ direction (dotted lines on patterns $\mathrm{a}$ and $\mathrm{b}$ ).

The transfer fidelity was further verified by Grazing Incidence Small Angle X-ray Scattering (GISAXS). The GI-SAXS patterns of both initial and final systems, collected at an incident angle of $0.2^{\circ}$, are reported in Figure 3. Before etching, the parallel diffraction rods located at $\mathrm{q}_{\mathrm{y}}=0.078 \mathrm{~nm}^{-1}$ are characteristic of homogeneous nanoperforated arrays with a periodicity of $80.6 \mathrm{~nm}$, in agreement with the pseudo hexagonal organization observed in the SEM micrographs. The presence of the diffraction rods is due to interference signals extending by evanescence through the layer, which is typical of a thin single layer of periodically organized motifs. After etching, the same diffraction peak is observed along 
the $\mathrm{q}_{\mathrm{y}}$ direction, as shown in the intensity profile curves of Figure 3c, indicationg that the initial organization has been retained.

The lateral organization of the perforated RNM has been transferred with high fidelity to the substrate. The disappearance of the diffraction rods in the $\mathrm{q}_{\mathrm{z}}$ direction (at $\mathrm{q}_{\mathrm{y}}=0.078 \mathrm{~nm}^{-1}$ ) is due to the significantly increased depth of the perforations. This disappearance stems from a higher absorption of the X-ray diffraction signal together with the augmentation of the in-plane interference frequency. The intense signal observed at low $\mathrm{q}_{\mathrm{y}}$ for the initial RNM corresponds to the specular reflection of the incident X-ray beam at the surface of the sample. This specular reflection is no longer observed after etching as a result of the increased roughness associated with the increase in the perforation depth that favors scattering.

The $\mathrm{Ca}_{0,5} \mathrm{Ti}_{0,5} \mathrm{O}_{1,5}$ RNM sample was exposed to a double exposure time (i.e. 2 cycles of program $\mathrm{OF}+\mathrm{O}$ ). The SEM image taken after etching (Figure 4a) reveals wells of around $350 \mathrm{~nm}$ deep. The walls tend to be thinner close to the surface and demonstrate interconnected wells. The fact that the etching depth did not double proportionally with the length of etching time is due to decreasing etching rate with well depth. The non-linear etching rate is attributed to decreased etchant diffusivity and by-product evacuation. This phenomenon is also responsible for a faster lateral etching rate at the top of the etched surface than at the bottom. ${ }^{28}$ For such reasons, the second cycle does not etch with the same anisotropy as the first cycle. A thin nanoperforated membrane is clearly observed standing on the perforated array in Figure 4a. It is likely that this membrane is remaining from the initial RNM. Indeed, the GI-WAXS analysis of this sample is shown in Figure 4b,c and reveals one diffraction peak located at $2 \theta^{\circ}=29^{\circ}$ that does not correspond to $\mathrm{Si}$, or any titanium oxide containing phase, but to the (111) plans of the fluorine $\mathrm{CaF}_{2}$ structure. The initial $\mathrm{Ca}_{0,5} \mathrm{Ti}_{0,5} \mathrm{O}_{1,5} \mathrm{RNM}$ is thus transformed into crystalline $\mathrm{CaF}_{2}$ during the reaction with the fluorinated plasma. One can conclude here that the limiting factor in the RIE process through the RNM is the increased lateral etching rate above a critical depth, which is intrinsically related to this technology, but not to the stability of the $\mathrm{CaF}_{2}$ nanomask. Thus faithful anisotropic transfer is limited to $250 \mathrm{~nm}$ for this diameter of nanoperforations. Depth could surely be improved if 
either diffusion were improved or if etching were slowed to provide time for reactant/product site exchange. Since the thickness of mask is close to $10 \mathrm{~nm}$ while the anisotropic etching rate was measured to be at least $250 \mathrm{~nm}\left(1\right.$ cycle), it is safe to state that the etching rate selectivity between $\mathrm{CaF}_{2}$ and $\mathrm{Si}$ is at least $25: 1$.

Considering the potential applications of the resulted silicon nanostructures the removing of the residual $\mathrm{CaF}_{2}$ mask can be necessary. After etching the $\mathrm{CaF}_{2}$ layer was dissolved by dipping the sample into a nitric acid solution (3M) for 1 hour. The complete removing was also verified by GI-WAXS; after dissolution no characteristic peaks of $\mathrm{CaF}_{2}$ were found anymore.
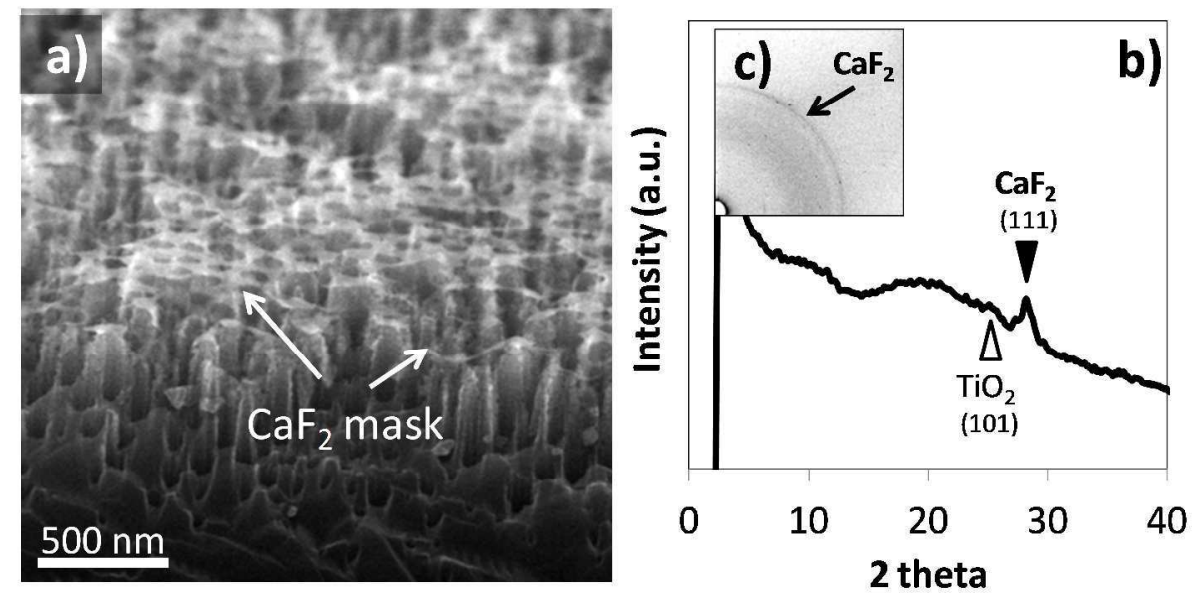

Figure 4. (a) An SEM micrograph showing an over-etched Si surface with a thin remaining perforated $\mathrm{CaF}_{2}$ layer resulting from the reaction of the RNM with the plasma. (b) GI-WAXS diffraction rings that reveal the presence of crystalline $\mathrm{CaF}_{2}$ remaining from the etched mask. (c) The faint and broad X-ray peaks observed at $2 \theta=20^{\circ}$ and $2 \theta=25^{\circ}$ can respectively be attributed to amorphous silica based materials and to traces of anatase $\mathrm{TiO}_{2}$ crystals remaining from the initial RNM mask.

\subsection{Influence of the Initial Calcium Content}

The efficiency of similar RNM systems having large perforations and different $\mathrm{Ca}^{2+}$ content were then verified by submitting to RIE in lower RF mode. It is important to point out that in this case longer 
exposure time (4 minutes) was required compared to high RF mode. ${ }^{25-26}$ In particular OF + Qeconditions could not be adapted to the lower RF mode and the passivating $\mathrm{O}_{2}$ gaseous component of the atmosphere was exchanged by $\mathrm{CHF}_{3}$ (see CF program description in Table 1). Figure 5 shows a sequence of SEM images of the transferred pattern of three different samples etched with the program CF (1 cycle each) and using a $\mathrm{Ca}_{\mathrm{x}} \mathrm{Ti}_{(1-\mathrm{x})} \mathrm{O}_{(2-\mathrm{x})} \mathrm{RNM}$ with $\left.\mathrm{x}=\mathrm{a}, \mathrm{d}\right) 0.375$; b,e) 0.250; and c,f) 0.125.
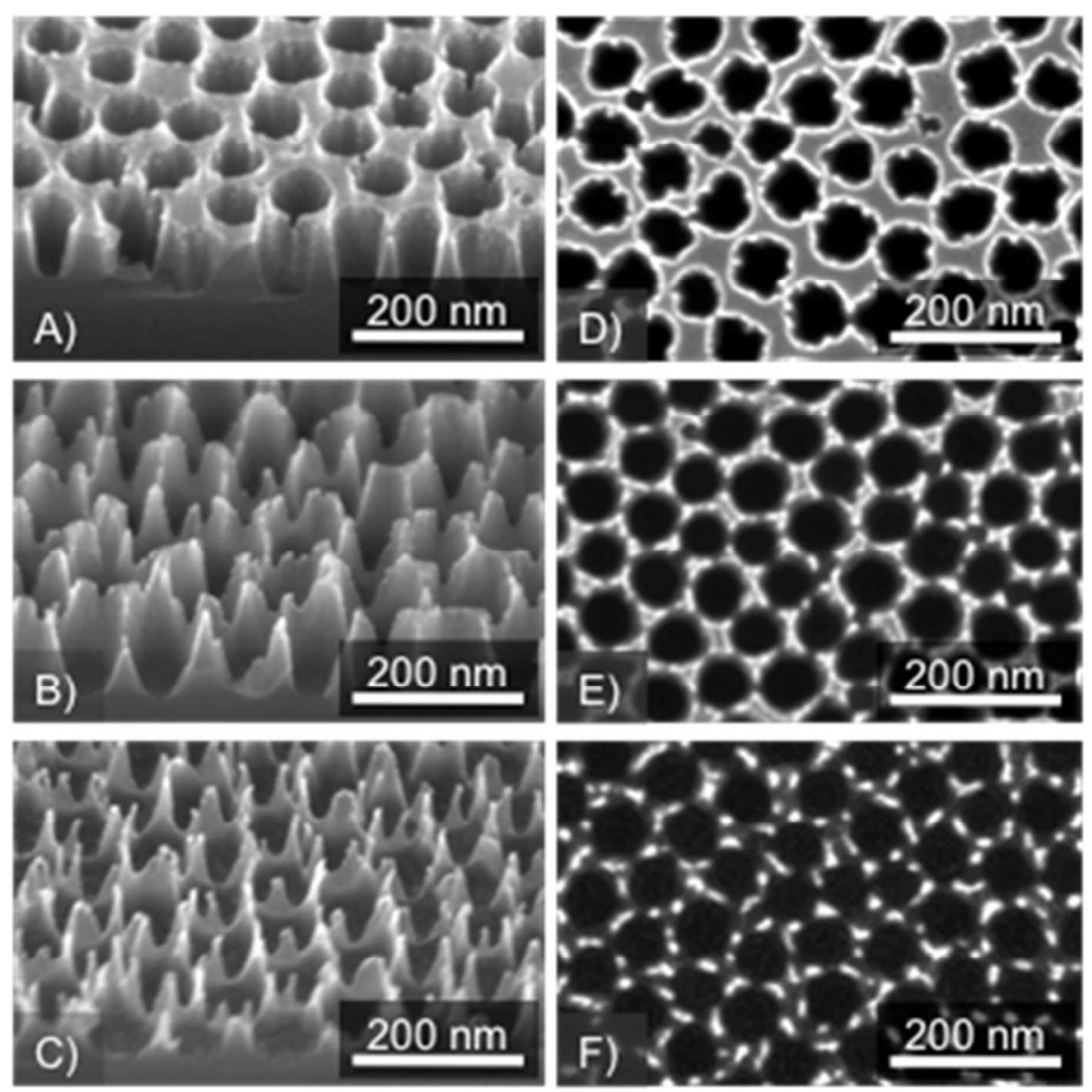

Figure 5. SEM images of the transferred patterns obtained using the CF program and Ca content of $(a, d) x=0.375 ;(b, e) x=0.250$; and $(c, f) x=0.125$. Images $a, b$ and $c$ are taken at an angle of $45^{\circ}$ while images $\mathrm{d}$, e and $\mathrm{f}$ were collected at $0^{\circ}$ angle.

For $\mathrm{x}=0.375$, no significant difference is observed compared to the previous pattern transfer obtained for $\mathrm{x}=0.5$ with program $\mathrm{OF}$. However, the maximum etching depth obtained in these conditions, before alteration of the wells' morphology, was $160 \mathrm{~nm}$ with $4 \mathrm{~min}$ of program $\mathrm{CF}$. At lower concentrations of 
$\mathrm{Ca}$ in the RNM $(\mathrm{x}=0.25$ and $\mathrm{x}=0.125)$, a replicate transfer of the mask is no longer possible Narrodver intercavity walls and sharp needles are obtained upon decreasing the Ca content. It is reasonable to assume that these patterned morphologies resulted from the $\mathrm{CaF}_{2}$ nanomask becoming increasingly disconnected with decreasing $x$ value. In particular discrete $\mathrm{CaF}_{2}$ nanoparticles were produced from lower $\mathrm{Ca}^{2+}$ content, leading to the formation of needles (see Figure $5 \mathrm{~b}$ and $\mathrm{c}$ ) upon etching. This result confirms the stability and the protective role of the $\mathrm{CaF}_{2}$ phase in the RIE process. However, it also reveals that when $\mathrm{Ca}$ quantities are too low, only small domains of $\mathrm{CaF}_{2}$ (disconnected nanoparticles) can be stabilised upon reaction with the plasma, and an exact transfer of the initial RNM is not obtained.

\subsection{Second example of patterning: Silicon Nanopillars}

Since one can transform the initial $\mathrm{Ca}_{\mathrm{x}} \mathrm{Ti}_{(1-\mathrm{x})} \mathrm{O}_{(2-\mathrm{x})} \mathrm{RNM}$ into homogeneous dispersions of $\mathrm{CaF}_{2}$ nanoparticles, it must be possible to use them as particulate nanomasks to produce an array of nanopillars as illustrated in Figure 1 (route ii). In this last experiment, $\mathrm{Ca}_{0,5} \mathrm{Ti}_{0,5} \mathrm{O}_{1,5} \mathrm{RNM}$ were prepared using the smaller $\mathrm{PB}_{112} \mathrm{PEO}_{227}$ block copolymer as a template, which led to perforations of $35 \mathrm{~nm}$ in diameter, having a periodicity centered at $46 \mathrm{~nm}$ as determined by the GI-SAXS pattern and SEM in Figure $6 \mathrm{a}$ and $6 \mathrm{~d}$. The etching has been applied using 4 cycles of the $\mathrm{OF}+\mathrm{O}$ program in high RF mode, which is expected to lead to an over etched surface as shown in Figure 2. However, the FEG-SEM image of the resulting surface displayed in Figure 6e, surprisingly shows a dense array of homogeneous $173 \mathrm{~nm}$ tall, thin pillars of around $21 \mathrm{~nm}$ in diameter corresponding to an aspect ratio equal to 8 . The GI-SAXS pattern of the final surface is reported in Figure $6 \mathrm{~b}$ and reveals wide diffraction peaks along the $\mathrm{q}_{\mathrm{y}}$ direction with $\mathrm{d}$-spacing centered around $45 \mathrm{~nm}$, similar to that of the initial RNM. The disappearance of the diffraction rods and the specular reflection along the $\mathrm{q}_{\mathrm{z}}$ direction is here again related to the etching depth and roughness. The broadness of the peak is due to the fact that the base of the pillars are randomly located within the initial RNM position, keeping thus the same average periodicity but with a broader distribution, which is also observed in the FEG-SEM image Figure 6e. 

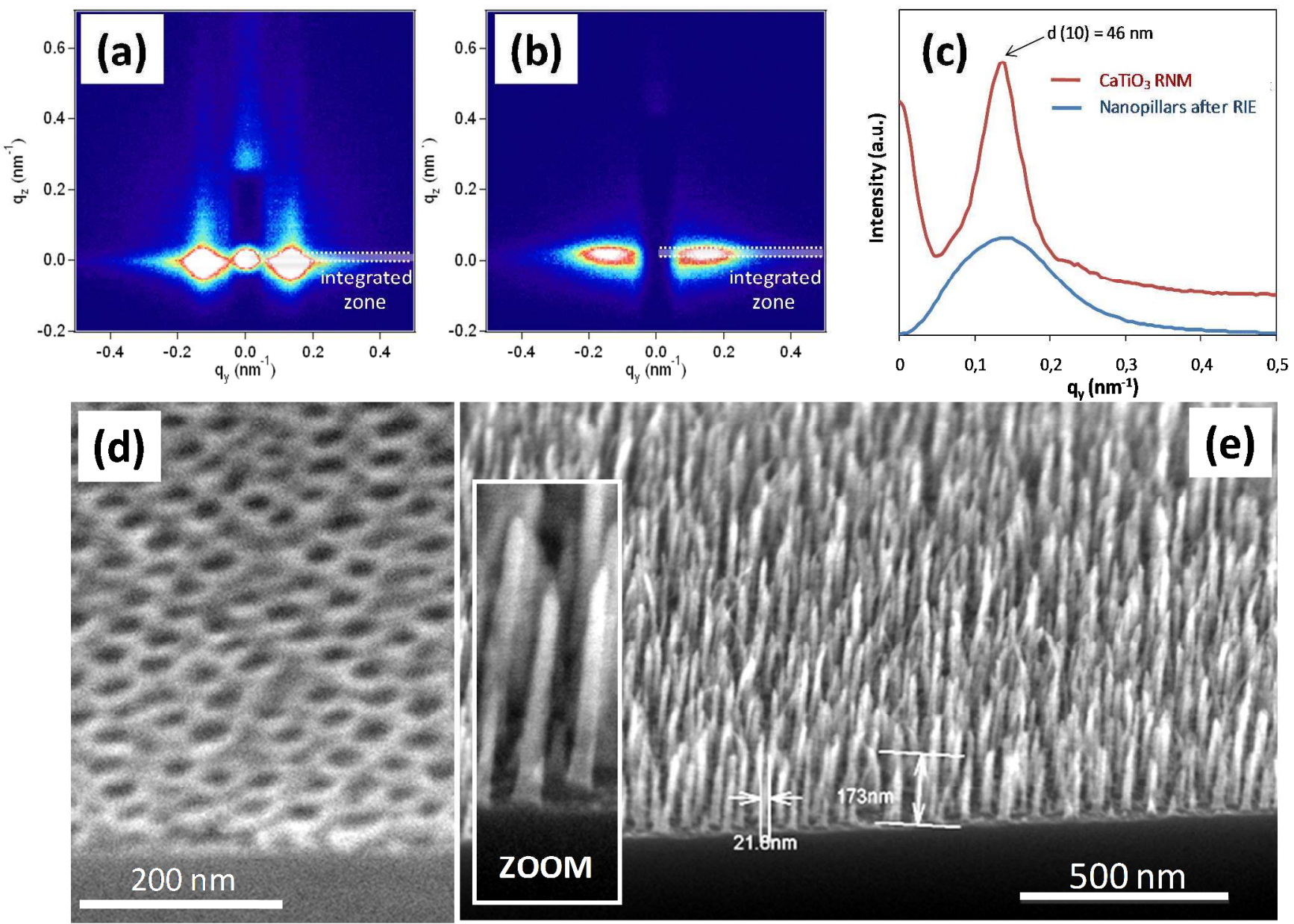

Figure 6. GI-SAXS patterns of (a) the initial $46 \mathrm{~nm}$ periodic RNM and (b) the final etched surface together with (c) the corresponding intensity profiles before (pink line) and after (blue line) etching along the $\mathrm{q}_{\mathrm{y}}$ direction (dotted lines on patterns a and b); SEM images of (d) the initial 46 nm periodic RNM film and (e) the surface after etching.

The motifs are more needle-like than pyramidal as a result of the less hindered diffusion of etchant and product around the pillars than in and out of the wells. The formation of the latter quasi-ordered nanopillar array can only involve the transformation of the nanoperforated $\mathrm{Ca}_{\mathrm{x}} \mathrm{Ti}_{(1-\mathrm{x})} \mathrm{O}_{(2-\mathrm{x})} \mathrm{RNM}$ into a discontinuous $\mathrm{CaF}_{2}$ nanoparticles distribution during the plasma etching, as already observed for low $\mathrm{Ca}$ content. However, the main differences here lie in the RNM content $(x=0.5 \mathrm{Ca})$, in the smaller perforation dimension and periodicity and in the longer etching time (4 cycles). It is thus likely that the combination of these is responsible for the final morphology. 
The solid RNM is rapidly transformed into solid $\mathrm{CaF}_{2}$ nanoparticles that mainly compose the resulting highly selective intermediate nanomask. At the same time the RIE process is taking place and nanowells start to be etched at the position of the nanoperforations. Upon longer treatment, titanium oxide is progressively eliminated from the mask and $\mathrm{CaF}_{2}$ domains start to sinter into more stable conformations i.e. arrays of discontinuous nanoparticles. Beyond this point, no more sintering is expected to occur and $\mathrm{CaF}_{2}$ particles are slowly eliminated by extensive ion etching. The average size of the nanoparticles depends on the separation distance of the initial RNM perforations (as long as they remain above the critical dimension for $\mathrm{CaF}_{2}$ nanoparticles stability), while their periodicity remains very close to that of the perforation correlation distance of the initial RNM. The faithful transfer of our RNM onto the Si wafer is thus a kinetic problem related to a delicate competition between the rate of $\mathrm{CaF}_{2}$ nanoparticle formation and the Si elimination rate. 


\section{Conclusions}

View Article Online

Adding $\mathrm{Ca}^{2+}$ to $\mathrm{TiO}_{2}$ INP created a RNM with high selectivity towards dry etching in fluorinated plasma. The calcium titanium oxide was transformed into a highly stable $\mathrm{CaF}_{2}$ mask. Depending on the dimensions of the initial INP perforations and on the initial calcium content in the $\mathrm{RNM}, \mathrm{CaF}_{2}$ organized into either a continuous ordered network or into a semi-random distribution of nanoparticles during etching with dimensions and periodicity directly related to that of the RNM. The resulting highly selective nanomasks can thus lead either to arrays of deep wells or nanopillar arrays. This novel concept combines simple self-assembly with RIE to achieve up to 1:25 selectivity, as low as $20 \mathrm{~nm}$ in the lateral dimensions of the motif, and $45 \mathrm{~nm}$ in lateral periodicity and up to 8 in aspect ratio. These novel RMNs are homogenous, robust, and they can be applied on a surface size limited only by the capacity of the RIE device. In addition the complete process (mask fabrication + dry etching) can be performed within only 15 minutes. This versatile approach is thus likely to be a promising candidate for the industrial large surface production of electronic and optical components. 


\section{Methods}

View Article Online

$\mathrm{Ca}_{\mathrm{x}} \mathrm{Ti}_{(1-\mathrm{x})} \mathrm{O}_{(2-\mathrm{x})} \mathrm{RNM}$ layers were prepared from calcium chloride and titanium chloride solutions in presence of micellar agents. Anhydrous calcium chloride (Aldrich, $1.3 \mathrm{~g}, 11.8 \mathrm{mmol}$ ) was dissolved in $20.3 \mathrm{~g}$ of absolute ethanol (GPR Rectapur, $442 \mathrm{mmol}$ ) and $3.35 \mathrm{~g}$ of titanium (IV) chloride (Warning: heat and $\mathrm{HCl}$ vapors evolve! Aldrich, $17.7 \mathrm{mmol}$ ) to make a stock solution. Poly(butadiene-blockethylene oxide, PB-PEO) (0.03 g) of either $15600 \mathrm{~g} \mathrm{~mol}^{-1}\left(\mathrm{~PB}_{112} \mathrm{PEO}_{227}\right.$, Polymer Source P2753) or $75500 \mathrm{~g} \mathrm{~mol}^{-1}\left(\mathrm{~PB}_{640} \mathrm{PEO}_{989}\right.$, Polymer Source P2325) was dissolved in ethanol $(5 \mathrm{~g})$ and purified water $(0.25 \mathrm{~g})$. This solution was heated to $45^{\circ} \mathrm{C}$ for 2 days to produce monodisperse micelles. The solution was allowed to cool to room temperature and then $0.37 \mathrm{~g}$ of the stock calcium chloride/titanium (IV) chloride solution was added dropwise. This was stirred for $1 \mathrm{~h}$ before dip-coating. The typical molar ratios of the initial solutions was $1-\mathrm{x} \mathrm{TiCl}_{4} / \mathrm{x} \mathrm{CaCl}_{2}(0.12<\mathrm{x}<0.5) / 0.75 \mathrm{EO} / 40 \mathrm{H}_{2} \mathrm{O} / 215 \mathrm{EtOH}$ (EO corresponds to the ethylene oxide units of the PEO chain). The silicon substrates were first washed with acetone, $3 \mathrm{M} \mathrm{HNO}_{3}$, water, ethanol and then acetone before dip-coating the solution at a withdrawal speed of $0.55 \mathrm{~mm} \cdot \mathrm{s}^{-1}$ at $60{ }^{\circ} \mathrm{C}$ using a dip-coater built in-house with enhanced processing control. A thermal treatment at $500{ }^{\circ} \mathrm{C}$ for 5 mins was then applied under an infrared lamp. The samples were then anisotropically etched by reactive ion etching using $\mathrm{SF}_{6} / \mathrm{O}_{2}$ (program $\mathrm{OF}$ ) or $\mathrm{SF}_{6} / \mathrm{CHF}_{3}$ (program $\mathrm{CF}$ ) gas mixture by using either a Plassys Reactive Ion Etcher or a Nextral NE100 Reactive Ion Etcher in CCP mode. The RIE conditions (power, gas flux, pressure and time) are reported in Table 1. The higher RF power used in the OF and $\mathrm{O}$ programs are responsible for the higher etching rates in these case. OF and $\mathrm{O}$ programs have been developed for high selectivity etching of silicon as compared to a photoresist. ${ }^{29}$ After etching the residual $\mathrm{CaF}_{2}$ layer was dissolved by dipping the sample into a nitric acid solution (3M) for 1 hour. ${ }^{30}$

X-ray analyses were performed by grazing incidence small-angle X-ray scattering (GI-SAXS); a Rigaku S-max 3000 equipped with a microfocus source $\lambda=0.154 \mathrm{~nm}$ and a $2 \mathrm{D}$ Gabriel type detector place at $1480 \mathrm{~mm}$ from the sample (all under vacuum), at an incident angle of $0.20^{\circ}$. The direct and 
specular reflected beams were masked by a vertical beam-stop. Wide angle X-ray scattering (GIWAXS) was the same set-up as the GI-SAXS except that diagrams were obtained by radial integration of the signal obtained on a image plate placed at $5 \mathrm{~cm}$ from the sample centre. Inspection of the samples was carried out by high resolution field emission gun scanning electron microscopy (FEG-SEM), a Magellan 400L- FEI.

\section{Acknowledgment}

Mohamed Selmane, of the Laboratoire Chimie de la Matière Condensée, performed all of the GISAXS and GI-WAXS measurements and helped with analysis. CNRS, the UPMC, and the Collège de France provided funding and facilities. A.A.L. thanks Saint-Gobain Recherche for funding. 
References

(1) M. E. Stewart, M. J. Motala, J. Yao, L. B. Thompson and R. Nuzzo, Proceedings of the Institution of Mechanical Engineers, Part N: Journal of Nanoengineering and Nanosystems 2007, 220, 81.

(2) Towards Green Electronics in Europe, Strategic Research Agenda Organic \& Large Area Electronics, in http://www.photonics21.org/download/olae_sra.pdf 2009.

(3) Y. Xia, J. A. Rogers, K. E. Paul and G. M. Whitesides, Chem. Rev. 1999, 99, 1823.

(4) J. M. Gibson, Phys. Today 1997, 56.

(5) S. Y. Chou, P. R. Krauss, W. Zhang, L. Guo and L. Zhuang, J. Vacuum Sci. Technol. B 1997, 15, 2897.

(6) C. Vieu, F. Carcenac, A. Pepin, Y. Chen, M. Mejias, A. Lebib, L. Manin-Ferlazzo, L. Couraud and H. Launois, Appl. Surface Sci. 2000, 164, 111.

(7) H. Kim, S.Park and W. Hinsberg, Chem. Rev. 2010, 110, 146.

(8) D. Grosso, F. Ribot, C. Boissière and C. Sanchez, Chem. Soc. Rev. 2011, 40.

(9) A. Sinitskii, S. Neumeier, J. Nelles, M. Fischler and U. Simon, Nanotechnology 2007, 18, 305307.

(10) L. Li, T. Zhai, H. Zeng, X. Fang, Y. Bando and D. Golberg, J. Mater. Chem. 2011, $21,40$.

(11) S. Krishnamoorthy, K.K. Manipaddy and F.L. Yap, Adv. Funct. Mater. 2011, 21, 1102.

(12) B. Paivanranta, P. K. Sahoo, E. Tocce, V. Auzelyte, Y. Ekinci, H. H. Solak and C.C Liu, K.O. Stuen, P.F. Nealey and C. David, ACS Nano 2011, 5, 1860.

(13) R.A. Farrell, N.T. Kinahan, S. Hansel, K.O. Stuen, N. Petkov, M.T. Shaw, L.E. West, V. Djara, R.J. Dunne, O.G. Varona, P.G. Gleeson, S.J. Jung, H.Y. Kim, M.M. Koleśnik, T. Lutz, C.P. Murray, J.D.Holmes, P.F. Nealey, G.S. Duesberg, V. Krstić and M.A.Morris, Nanoscale, 2012, 21, 3228.

(14) C. Tang, E. Lennon, G.H. Fredrickson, E.J. Kramer and C.J. Hawker Science 2008, 322, 429.

(15) S.G. Cloutier, P.A. Kossyrev and J. Xu, Nat. Mater. 2005, 4, 887.

(16) Z. Huang, X. Zhang, M. Reiche, L. Liu, W. Lee, T. Shimitzu, S. Senz and U. Gosele Nanoletters 2008, 8, 3046.

(17) A. Fisher, M. Kuemmel, M. Jarn, M. Linden, C. Boissiere, L. Nicole, C. Sanchez and D. Grosso, Small 2006, 4, 569.

D. Grosso, J. Mater. Chem. 2011, 21, 17033 
(19) M. Kuemmel, J. Allouche, L. Nicole, C. Boissière, C. Laberty, H. Amenitsch, C. Sanchez and D. Grosso, Chem. Mater. 2007, 19, 3717.

(20) J. Allouche, D. Lantiat, M. Kuemmel, M. Faustini, C.L. Robert, C. Chaneac, E.Tronc, C.Boissiere, L. Nicole, C. Sanchez and D. Grosso, J. Sol-Gel Sci. Technol. 2010, 53, 551.

(21) M. Jarn, F.J. Brieler, M. Kuemmel, D.Grosso and M. Linden, Chem. Mater. 2008, 20, 476.

(22) M. Faustini, L. Nicole, C. Boissiere, P. Innocenzi, C. Sanchez and D.Grosso, Chem. Mater. 2010, 22, 4406.

(23) C. Laberty-Robert, M. Kuemmel, J. Allouche, C.Boissiere, L. Nicole, D. Grosso and C. Sanchez J. Mater. Chem. 2008, 18, 1216.

(24) M. Faustini, B. Marmiroli, L. Malfatti, B. Louis, N. Krins, P. Falcaro, G. Grenci, C. LabertyRobert, H. Amenitsch, P. Innocenzi and D. Grosso, J. Mater. Chem. 2011, 21, 3597.

(25) S. Hollydays and A.Stanishevsky, Surface Coatings Technol. 2004, 188-189, 741.

(26) G. Pfaff, Chem. Mater. 1994, 6, 58.

(27) M. Zhang, J.Z. Li, I. Adesida and E.D.Wolf,. J. Vac. Sci. Technol. B 1983, 1, 1037.

(28) R. Legtenberg, H. Jansen, M. d; Boerand M. Elwenspoek, J. Electrochem. Soc. 1995, 142, 2020.

(29) A.A. Letailleur, K. Nomenyo, S. McMurtry, E. Barthel, E.Søndergård, G. Lérondel, G. J. Appl. Phys. 2011, 109, 16104.

(30) C. Motzer and M. Reichling J. Appl. Phys. 2009, 105, 64309. 
SYNOPSIS TOC. Novel sol-gel derived reactive nanomasks were used for dry etching of silicon allowing the formation of nanowells or nanopillars.
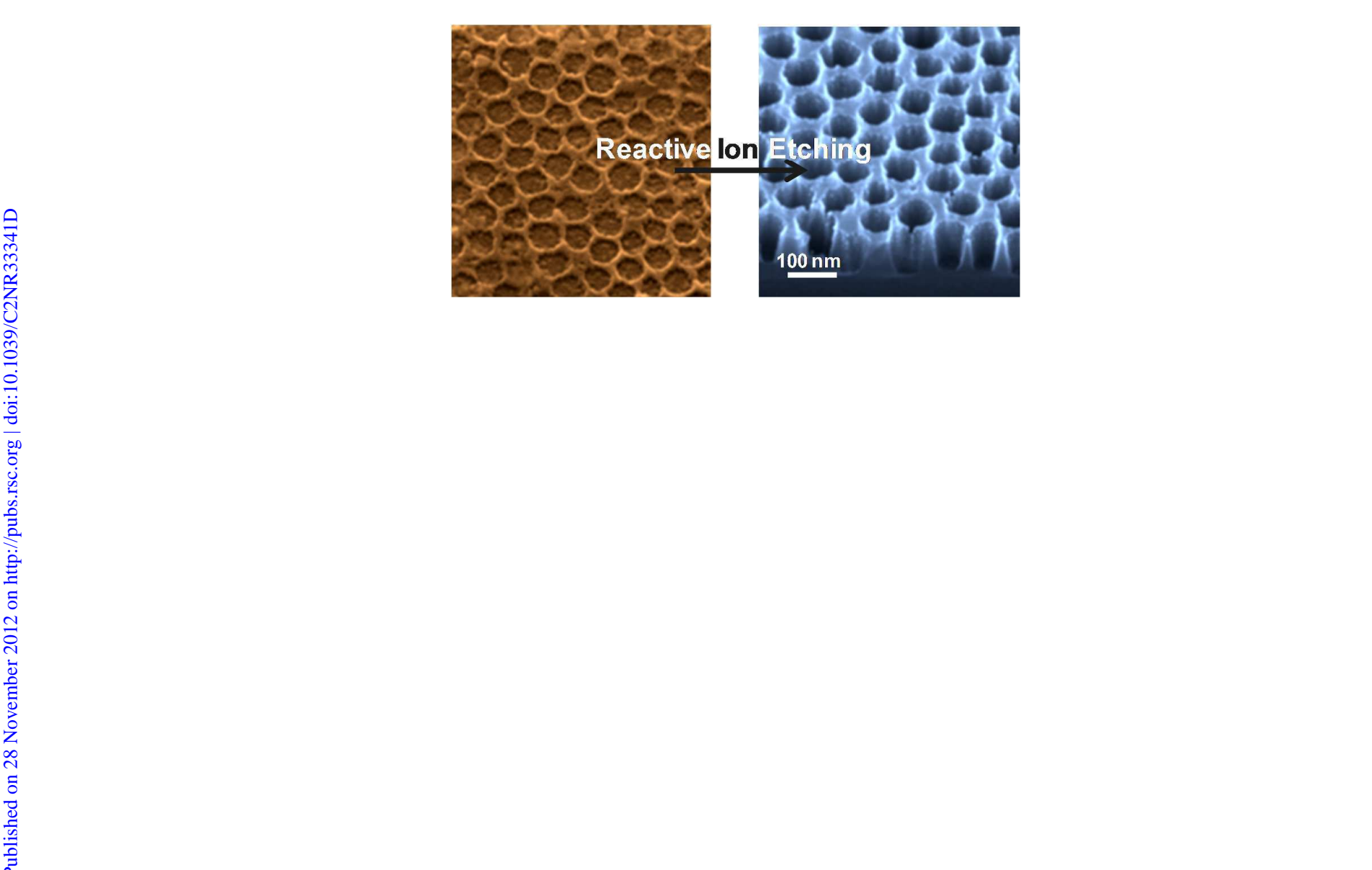